\title{
Exploring the Status Quo of Water-Energy Nexus Policies and Governance in Jordan
}

Raya A. Al-Masri*, Jonathan Chenoweth, Richard J. Murphy

Centre for Environment and Sustainability, University of Surrey, Guildford, Surrey, GU2 7XH, UK

* Corresponding author. E-mail address: r.al-masri@,surrey.ac.uk

The Water-Energy Nexus (WEN) is broadly defined as an integrated paradigm for efficiently managing water and energy resources. While several studies have investigated WEN from a resource efficiency perspective, little research has focused on governance and policy integration aspects. In this study, the level of understanding of WEN in Jordan is examined for the first time from the perspective of governance and public policy development. We explored institutional and policy integration gaps between the two sectors by mapping the water and energy policies in Jordan, and holding semi-structured interviews with the key policymakers and stakeholders. While the awareness of the nexus paradigm by officials is increasing, the level of knowledge about WEN varies across the sectors. As water and energy policies are formulated independently, there are no formal mechanisms for collaboration in the policy formulation and implementation processes, nor formal mechanisms for collaboration to guarantee policy effectiveness. Factors such as acknowledging shared understandings between different actors, setting flexible policy boundaries, and introducing specific capacity building plans at the institutional level are identified as critical to enable better WEN governance. Proposals from this study recommend adopting collaboration arrangements tailored to each sector's needs and existing structures, and supported by effective enforcements to ensure an incremental and steady change toward inter-institutional coordination. A 'multi-layer approach' involving appropriate legal and policy frameworks, and adequate buman and financial resources; essentially from private sector is suggested. Proposals from this study can help policymakers to effectively plan for joint water-energy investments for a more sustainable future.

Keywords: Water-Energy Nexus; Water Policy; Energy Policy; Resources Governance; Sustainability; Water-deprived Countries

\subsection{INTRODUCTION}

Demanding livelihood patterns, population growth, and climate change have put natural resources including water and energy under pressure. Shifting from the 'silo policy thinking' to an 'integrated-holistic thinking' approach is therefore gaining attention from researchers and policymakers alike. The terms 'nexus' and 'nexus thinking' emerged in the early eighties and nineties as an innovative and integrated approach to tackling complex challenges (Boas et al., 2016; Endo et al., 2017; Hussey and Pittock, 2012; Kim et al., 2015). The 'Energy-Food' nexus first announced in 1983 (Endo et al., 2017) and later considered in its broader context involving the ecosystem (Boas et al., 2016). In the mid-eighties, acknowledgment of Water-EnergyAgriculture' nexus started to emerge (Scott et al., 2015), while around the early 2000s the 'WaterEnergy Nexus' (WEN) gained its explicit recognition (Scott et al., 2015) as a means to efficiently manage water and energy in an integrated way. In this study, the WEN is considered as a paradigm to understand coupled water and energy challenges in the developing countries, paying particular attention to the policy solutions, institutional structures and intersectionality, and other governance arrangements and challenges. Simply put, understanding the institutional intersection and potential synergies between the two sectors, in order to find commonalities and minimize trade-offs subject to their connection. This contributes to intertwining the different views and activities of the stakeholders engaged in managing those two sectors, toward achieving sustainable outcomes (Al-Saidi and Elagib, 2017; Boas et al., 2016; Endo et al., 2017).

Until recently, the majority of WEN studies have been addressing the subject from its technical aspects and resource use efficiency perspective (Scott et al., 2011). Hamiche et al. (2016) summarized studies that investigated the linkage between the technological and environmental dimensions in the WEN (e.g., see Cohen et al., 2004; Horvath, 2005; Leavesley et al., 1996; Lundie et al., 2004). They found that those studies adopted merely quantitative models; chiefly addressing the technological dimension of the nexus, with little consideration of the environmental and economic aspects of that. Social, institutional, and political dimensions though rarely featured (Hamiche et al., 2016). This has provided researchers and policymakers with a considerable analytical insight on the WEN (Weitz et al., 2017a), and drives scholars to undertake further research in this regard. 
Equally important to understanding the WEN from a technical perspective is capturing the institutional and decision-making (Scott et al., 2011), policy, and governance dimensions of the nexus (Hoff, 2011). Al-Saidi and Elagib (2017) investigate integration in the nexus paradigm, as a new perspective on the management of the nexus. Their findings revealed the absence of a consistent definition for the integrative approach within the nexus across literature, and that nexus governance is overlooked in this debate. They conclude that time is still needed to acknowledge the worthiness of the integrative concepts in this regard (e.g., policy debate, new innovative concepts, reform roadmaps, etc.). Scott et al. (2011) explore the policy and institutional dimensions of the WEN through case studies in the USA. They highlight the lack of research considering the joint management of water and energy resources, and demonstrate the significance of adopting coupled institutional reforms within the two sectors policy frameworks. Their work emphasizes the need to explicitly embed the institutional and decisionmaking mechanisms alongside other analytical approaches (e.g., input-output relationships) in the WEN debate. Weitz et al. (2017a) provide insights on the nexus governance from an integrative governance perspective. They argue that despite the importance of the analytical insights in understanding the nexus, addressing the governance gap in the nexus debate enhances the effectiveness and accountability of policy management in this regard. Weitz et al. (2017a) conclude that while options to overcome policy incoherence in the nexus management are adequately proposed in the literature, some remain disconnected from the actual decisionmaking processes; thus, are ineffective. Elaboration to overcome this gap is further outlined. White et al. (2017) address water-energy-food nexus governance issues through qualitative and case study analysis. In their area-specific research, they investigate how those related-systems are institutionally connected in Phoenix, Arizona, and provide an understanding of the coupled challenges and opportunities of the nexus, specifically in the Phoenix Active Management Area, via stakeholder identification and analysis.

Notwithstanding the above, research on WEN governance and policy integration aspects, particularly in the developing world, is scant (Al-Ansari et al. 2015; Al-Zu'bi and Keough, 2015; Daher and Mohtar, 2015; Hoff et al., 2019). Siddiqi and Anadon (2011) explore the WEN in the Middle East and North Africa (MENA) region. They quantitatively evaluate the interrelationship between water and energy systems and the implications of water supply on energy systems in some Arab countries, via consumption analysis. Their evaluation revealed that there is heavy dependency on energy for water access, production, and groundwater abstraction across the region, besides high demand of energy for desalination in some countries. The opposite is true for water use in the energy systems, which makes the WEN highly skewed in the studied countries. While general policy proposals are outlined, their work lacks a detailed investigation of coupled water and energy infrastructure policies and decision options, the climate change policy dimension in the water and energy polices, and the role of stakeholders engagement in advocating better nexus management. Siddiqi et al. (2013) address the latter gap and investigate water-energy couplings and the relationship between different actors and stakeholders in Jordan. They apply concepts from 'stakeholders theory', and explore how 'organization theory of boundary-spanning agents' paradigms could enhance the interconnections between decision makers in the water and energy sectors toward formulating and implementing integrated policies. Siddiqi et al. (2013) find that water and energy requirements for a number of strategic infrastructure developments in Jordan are linked (e.g., an oil-shale development project, which would demand water, yet, would provide energy for other water supply options such as desalination). Such interlinked arrangements provide a promising platform for collaboration between decision makers in the two sectors, and call for jointplanning efforts to produce long-term integrated policies for sustainability. Hoff et al. (2019) investigate five resources-linked case studies in the MENA to bridge the gap in the limited availability of practical and evidence- based studies on the merits of the nexus approach, which diverts away the political will needed to develop robust governance structures for adequate nexus 
application (Hoff et al., 2019). Through an analytical framework, cases such as solar water pumping and irrigation in Morocco and solar desalination in Jordan inform nexus policymakers by highlighting the benefits of adopting a resources-nexus approach that promotes resource security and reduces decoupling, thereby improving policy and decision-making (Hoff et al., 2019). Hoff et al's. (2019) conclusions appreciate the promising technical solutions of the nexus between water, energy, and food (e.g., solar-powered desalination and irrigation), but also underscore the need to improve the horizontal and vertical policy coherence among the stakeholders involved. Aligning nexus-solutions with adequate policies, regulations, institutional measures, and monitoring mechanisms (Hoff et al, 2019) helps to curtail potential rebound effects (e.g., higher abstraction of water due to cheaper energy cost from solar) and support overall sustainability. The question that remains, however, is: how can this institutional and policy integration be achieved?

This study explores the WEN management in Jordan. It evaluates the status quo of the policies and institutional structures of the water and energy sectors, and whether they can be oriented toward an integrated governance of the WEN. The study contributes to two main gaps in the WEN literature; the limited available studies on the institutional and governance aspect of the WEN, and the shortage in qualitative research in this area, particularly in the Middle East region. Jordan is selected as a case study to understand the state of the WEN governance in the developing world. Jordan is a resources-deprived country with limited rainfall, water, and energy resources. The lack of integration between the water and energy sectors at the policy making and planning levels, besides leading to ineffective cooperation between several institutions, influences resources deficits and scarcity in the country. As a model of safe country from the Middle East region, findings of this study will help expand the debate on the WEN governance to other countries with similar conditions to the case presented here, in the region and beyond.

The paper first investigates the interlinkages in the key water and energy policies and strategies in Jordan to understand the level of interdependency between the two sectors at the policy level, and to identify gaps in the policy documents. The paper also examines the perspective and level of understanding of the sectors' policymakers on the WEN in terms of institutional collaboration, governance, and planning; and the key barriers and opportunities for effective WEN coordination between the water and energy sectors. The paper concludes by identifying proposals to foster better institutional cooperation and policy integration toward an integrated WEN governance and management.

\subsection{WEN Governance: Institutional Integration and Public Policymaking Perspectives}

Several scholars agree that policy fragmentation and inconsistency in the process hinder an effective adoption of nexus thinking across sectors (Weitz et al., 2017a; Weitz et al., 2017b). Nonetheless, little research has investigated what policy integration and coherence entails (AlSaidi and Elagib, 2017; Weitz et al., 2017a; Weitz et al., 2017b), or has provided views on how collaboration can be achieved (Weitz et al., 2017a; Weitz et al., 2017b). Scott et al. (2011) stress the importance of integration among different actors to help the nexus achieve its influence (Weitz et al., 2017a). Scott et al. (2015) propose three perspectives to study the institutional aspect of WEN: (i) the "institutional 'levels' structure", (ii) the "institutional functions", and (iii) "human needs and wants". The "institutional 'levels' structure" perspective assumes that different entities have different institutional and organizational processes (Scott et al., 2015) tailored to their own priorities and needs for providing the service (Al-Saidi and Elagib, 2017). This consequently reflects on the coordination between those institutions, or the lack thereof, in the adoption of combined guiding rules for water and energy resources management (Kim et al., 2015), and challenges the convergence of the two sectors (Al-Saidi and Elagib, 2017). The "institutional functions" perspective investigates the role of government entities in resource 
management, and their relation with private entities and NGOs to boost economic production and social integration (Kim et al., 2015; Scott et al., 2015). The third perspective deals with the relation between institutions and human needs and wants (Kim et al., 2015; Scott et al., 2015). Studying the level of institutional integration among these levels and examining how they interact within and across sectors would provide insight on how to eliminate tension among the different entities (whether governmental, private, or NGOs), and how to foster management collaboration and coordination among departments and ministries (Scott et al., 2015).

Weitz et al. (2017a) investigate the potential for incorporating the literature on the integrative environmental governance (IEG) concept into nexus research, and examine factors that would support linking the nexus to policy and decision-making processes. According to Weitz et al. (2017a), factors such as acknowledging the shared views and ideas between different actors, as a channel for collaboration, and increasing communication on shared principles between different competing institutions or stakeholders could achieve better connection between the decisionmaking processes and WEN governance and planning. Another key aspect is considering the process of achieving policy coherence as an ongoing flexible process, and clearly discussing and setting the levels/boundaries of compromise (e.g., flexible structuring boundaries) with other sectors, in order to allow for better policy coherence, or fragmentation as a trade-off in some contexts (Weitz et al., 2017a). In this vein, Pahl-Wostl et al. (2018, p. 162) argue that the "leeway for adjustment" has still not materialized at the horizontal policy coherence level, which, in turn, challenges the provision of a structured implementation of cross-sectoral policies vis-à-vis the WEN.

A key factor that hinders the effective implementation of the nexus goals is policy fragmentation, in which nexus considerations are not intertwined with decision-making and public policymaking processes (Gain et al., 2015; Kim et al., 2015). Policy fragmentation, particularly in developing countries, stems from conflicting interests (Weitz et al., 2017a), conflicting or overlapping regulatory margins, and insufficient collaboration amongst line ministries and actors (Kim et al., 2015), besides other political (Nilsson and Persson, 2003) and socio-economic factors. See examples from Bangladesh (Gain et al., 2015), Lebanon (Farajalla et al., 2016), The Lower Mekong Basin (Hensengerth, 2015), and Qatar (Daher and Mohtar, 2015)).

The literature agrees that the policy integration process entails a holistic understanding of the different factors and contexts that could influence policy development and implementation (Miles et al., 2001 in Gain et al., 2015). This covers political, economic, environmental, and social factors that have the potential to impact public policymaking at several levels. Gain et al.'s (2015) work provides perspectives on the successful integration of policies or the development of new ones that are more coordinated for WEN governance in the developing world. According to Gain et al. (2015), identifying the institutions and stakeholders that would be involved in the decision-making process, providing insight on how decisions could be taken for the sectors under consideration, and conducting better assessments for the policy options, via research studies, scenario analyses, and impact assessments, would provide an opportunity for policymakers to develop better policy integration approaches. Bhaduri et al. (2015) underscore the positive impact local-level institutional changes and policy implementation can have on enhancing sustainable governance of resources, particularly where systems and services are vulnerable. The successful policy reform to monitor groundwater use in West Bengal, India, provides an example for effective nexus governance in this regard. New policy was framed in collaboration with the energy sector, where farmers pay electricity tariff for groundwater use based on metered consumption instead of a flat rate. Benefits of such local-level institutional arrangements include eliminating excessive extraction of groundwater, as major source for irrigation (Bhaduri et al., 2015), reducing losses in the energy sector due to metered pricing of electricity, and bridging the communication gap between water and energy sectors to jointly address shared challenges in the future. 
While the literature recognizes the merit of having strong policy, institutional, and decisionmaking linkages to the WEN (Hoff, 2011), it acknowledges the gaps in the theoretical (Allouche et al., 2015) and conceptual areas (Al-Saidi and Elagib, 2017; Benson et al., 2015; Foran, 2015) pertaining to the nexus. It highlights the need for further investigation in this regard (Al-Saidi and Elagib, 2017; Boas et al., 2016; Scott et al., 2011; Weitz et al., 2017a). Allouche et al. (2015) discuss the immaturity of the nexus concept at the governmental level. This suggests that nexus research needs to be reviewed in conjunction with other integrated management models, in order to better understand the positive contribution of nexus thinking. This would entail updating existing paradigms, capitalizing on the positive aspects of these, and modifying the shortfalls; thus, proposing policy or governance solutions responsive to the changing challenges of resources use (Al-Saidi and Elagib, 2017).

\subsection{STUDY CONTEXT}

\subsection{Overview of Jordan's Water and Energy Sectors}

Jordan is located in a semi-arid region, where the majority of the Kingdom receives less than 200 $\mathrm{mm}$ of rainfall a year (MWI, 2016b). The total long-term average annual rainfall volume of 8,191 mcm (MWI, 2015) accounts for less than $0.01 \%$ of the world's average (AQUASTAT, 2018), of which almost $92 \%$ is lost to evaporation (MWI, 2015). In 2015, the quantity of freshwater resources amounted to nearly $780 \mathrm{mcm}$ that is less than the recorded water demand of 1,400 mcm (MWI, 2015), which epitomize physical water scarcity. With less than an annual 100 $\mathrm{m}^{3} /$ capita (i.e., a share lower than the global threshold of severe water scarcity of $500 \mathrm{~m}^{3} /$ capita (MWI, 2016b)), Jordan is one of the poorest of countries in terms of water. The prolonged drought periods that have been hitting the country, the continuous influx of refugees that Jordan has been observing since 1948, and the impacts of climate change exacerbate the water burden in Jordan (Scott et al., 2003). Recently, the Syrian crisis added nearly 1.4 million refugees to the already growing population (MWI, 2016b), and further increased the pressure on the limited resources.

Jordan is heavily reliant on imports to meet its growing energy demand, which is expected to double to a forecasted 15.08 Mtoe by 2020 from 7.58 Mtoe back in 2007 (MEMR, 2016). In 2016, the total generated energy in the Kingdom, which is chiefly dependent on fossil fuel (MEMR, 2016, MWI, 2016a), amounted to 19,390 GWh, with a total production of around 19,012 GWh of electrical energy (MEMR, 2016). In 2016, combined cycle accounted for (54\%) of the electrical energy production by type, followed by steam units $(31 \%)$, and diesel engines by heavy fuel and diesel $(13 \%)$. Less than $(1 \%)$ of the total production of energy came from renewables including wind, solar, biogas, and hydro for the same period (MEMR, 2016). Of the total consumed electrical energy in Jordan, up to $15 \%$ goes to the supply of water, primarily water pumping (MEMR, 2016; MWI, 2015). Population growth, urbanization, and industrialization will pose additional pressure on energy supply, particularly if the current reliance on imported energy sources persists. When assessed in conjunction with other uncontrollable factors such as intractable conflicts in the region and the regular influx of refugees from neighboring countries, the demand for energy in Jordan is expected to grow over the coming decades.

\subsection{The Link between Water and Energy Sectors}

The water sector in Jordan is energy-intensive (Scott et al., 2003; Siddiqi et al., 2013). It consumes nearly $20 \%$ of the total energy and $15 \%$ of the total electricity (MEMR, 2016; MWI, 2016a), which makes it the largest consumer of electricity of all sectors. This is attributed to two main reasons. First, water is conveyed over long distances from the source to major points of consumption or use, which raises the energy consumption and adds significant cost to the sector (Scott et al., 2003). Moreover, water is pumped out of the renewable and non-renewable groundwater wells available across the Kingdom at deep elevations of nearly 400-500 m below 
the surface and extracted for water supply; a process that demands energy. Furthermore, given the topography of Jordan, there is a large elevation difference between where people reside and where the water sources are located (MWI, 2016a). This means that water is pumped up to $1,000 \mathrm{~m}$ elevation in some places, using large amounts of energy. Second, some of the existing dams in the country, which were originally used for irrigation supply, are recently being utilized as a source for domestic water supply, with the water requiring treatment. This implies more energy consumption for treatment purposes.

To meet its energy needs, the water sector relies on the energy provided by the electricity distribution companies serving the three regions of Jordan (central, northern, and southern regions), and the National Electric Power Company (NEPCO). The total annual energy bill that the sector pays amounts to $\$ 220$ million, which is nearly $60 \%$ of the total operating expenses of the Ministry of Water and Irrigation (MWI). This fiscal strain has occurred along with the need for further water and wastewater infrastructure to accommodate the continuous and rising demand in the country; therefore, has disrupted an effective implementation of the MWI plans and has affected delivery of the service (MWI, 2016a).

The lack of indigenous natural resources in Jordan has triggered the need to diversify waterenergy production systems to achieve cleaner and more sustainable supply. The country is moving forward in the implementation of mega projects such as desalination and a nuclear power reactor. Despite the interdependence between the water and energy sectors, it is assumed that the high level of independence between the two sectors at the policy making, governance, and planning levels will influence water-energy deficits in the country. On the one hand, according to the MWI and JAEC figures, the nuclear power reactor project would require 45 $\mathrm{mcm}$ of water annually for cooling and other uses in the nuclear station, of which $15 \mathrm{mcm}$ is to be acquired directly from fresh groundwater resources. Officials in the water sector argue that this quantity of water would be taken at the expense of the quantity assigned to the Jordan Valley, where water is mainly used for irrigation (MWI, 2016b). Irrigated agriculture in Jordan consumes nearly $51 \%$ of the total national available water (MWI, 2015). Jordan Valley contains nearly $40 \%$ of the irrigated agriculture and produces around $70 \%$ of the total agricultural productivity (MWI, 2016b). This signifies the importance of irrigated agriculture in the Jordan Valley area, and the need to maintain sufficient water availability to sustain this productivity in light of the high temperatures and low rainfall volumes. Ignoring this fact would negatively impact the food security and agriculture in the area, as a main driver for economic growth. In contrast, some energy experts argue that the use of groundwater for cooling purposes is not technically feasible, from a technical perspective due to the temperature of the groundwater. On the other hand, desalination is an energy-intensive solution (Pittock, 2011 in Hussey and Pittock, 2012), unless integrated into a renewable energy system to maximize its benefits for water supply. This gives an example on the disconnection and weak planning and coordination between officials of the two sectors that hinders the design and implementation of appropriate interventions for large investments.

\subsection{METHODOLOGY}

In this study, a qualitative approach was applied for data collection. This involved the utilization of primary sources (i.e., semi-structured interviews with the sectors' relevant players and policymakers, and direct observations), analysis of secondary sources (e.g., strategic planning documents, policy papers, action plans, among other publically available documents), and review of relevant literature.

\subsection{Detailed Policy Mapping and Analysis}

This involved identifying and critical analysis of the key policies and strategies prepared for water and energy in Jordan (Figure 1). The aim was to develop an understanding of the level of interdependence between water and energy in Jordan at the policy level, and to identify any gaps 
in the respective policies with regard to the WEN and the level of integration between the two sectors.

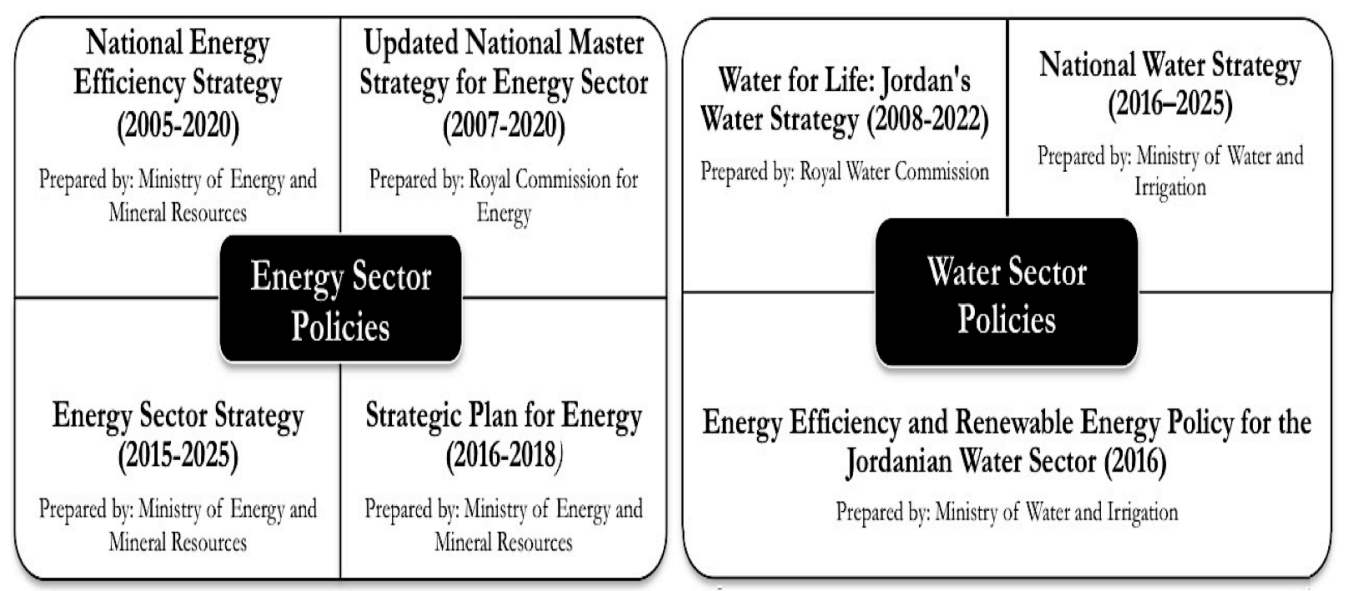

Figure 1: Water and Energy Policies and Strategy Documents Analyzed

The policies were assessed based on three main criteria:

- Main policy themes and objectives;

- The level and type of integration between water and energy, if any (e.g., physical, administrative, policy making level, etc.); and

- Gaps identification and analysis with regard to the WEN and the level of integration between the two sectors.

\subsection{Stakeholders Identification and Participants Selection}

A detailed mapping of the sectors stakeholders and potential interviewees was conducted using publicly available data and secondary sources. A list of the key players and stakeholders who are directly responsible for the planning, management, and implementation of programs and policies in the target sectors (i.e., energy, water, environment, sustainability, and sustainable development) (Figure 2) was prepared, along with a flexible plan with contingencies for meetings and appointments. The finalized list included the most relevant individuals and organizations defined as experts and government officials from each sector at the policymaking level (i.e. 'elite' group), together with local experts with exposure to the public policy formulation process and resources governance in Jordan.

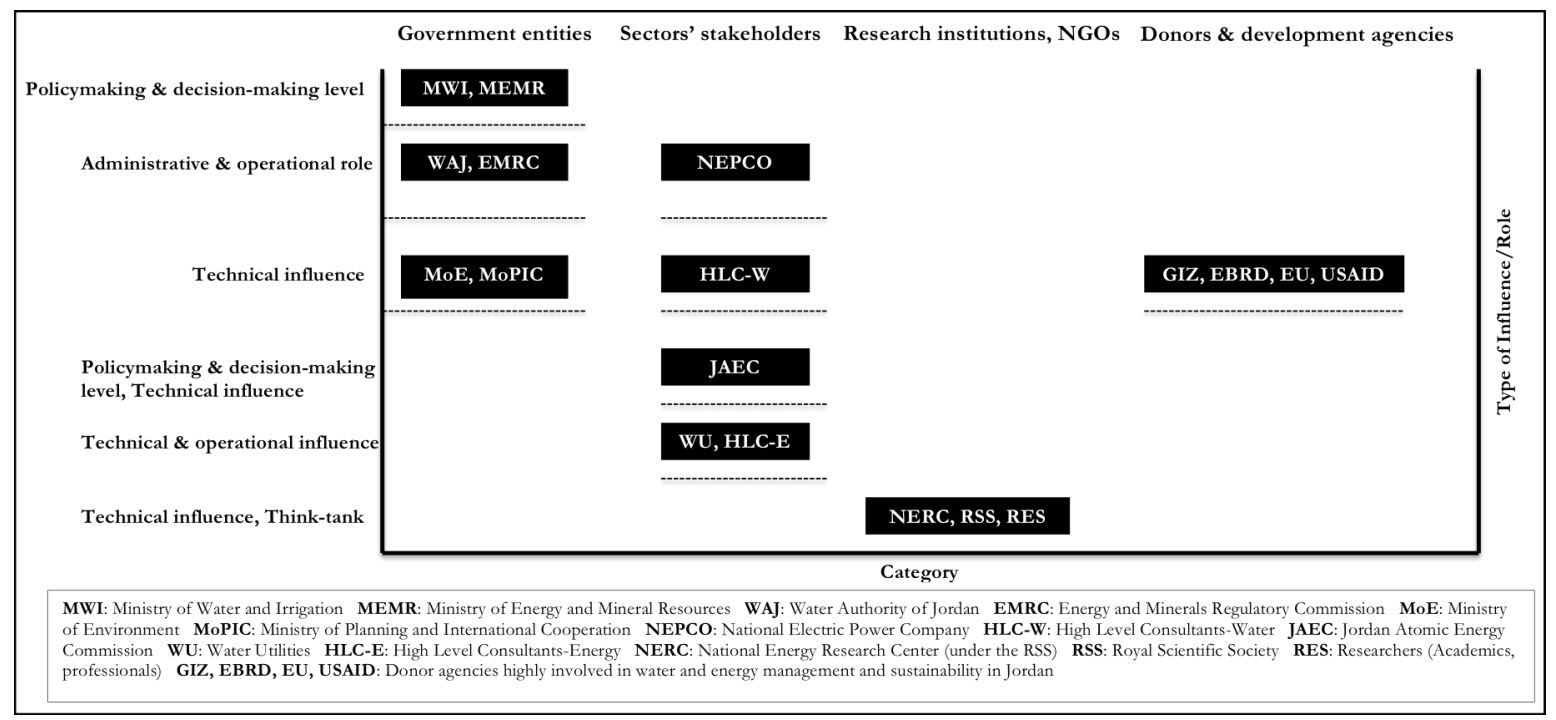

Figure 2: Key Stakeholders in the Water and Energy Sectors in Jordan 


\subsection{Data Collection and Analysis}

Data collection in Jordan was conducted in June 2017. Eight interviews were conducted with officials and experts in the water and energy sectors. These were, two government officials at the policy making level in the water and energy sectors; one senior level official at the MWI; one senior level official at the MEMR; one high level advisor to the minister of water; one international energy expert and former minister of energy and of water; one international water expert and former minister of water, and one senior level expert in sustainability, water, and energy issues in the non-government sector, with previous experience in the public sector. Table 1 shows the respondents coding system used throughout the analysis. Although officials were primarily selected from the prepared stakeholders' list, a 'snowballing' strategy was followed to secure interviews with other prominent experts. The diversity of the experience of the people interviewed helped the study team to capture different perspectives about WEN governance in Jordan. Moreover, interviews with senior experts who served as former ministers provided insight on the sector management and the public policy formulation processes. The experts were able to freely express their views about the sector challenges while reflecting on their actual experiences while working in the public sector.

Table 1: Respondents Coding System

\begin{tabular}{|c|c|}
\hline Code* & Organization \\
\hline WSO1 & MWI \\
\hline WSO2 & MWI \\
\hline FWSO & Senate House of the Jordanian Parliament \\
\hline ESO1 & MEMR \\
\hline SSN & NGOs for Sustainability \\
\hline FESO & Senate House of the Jordanian Parliament \\
\hline ESO2 & EMRC \\
\hline WSO3 & MWI \\
\hline
\end{tabular}

Semi-structured open-ended questions were used to guide the conversation during the interview. Questions were formulated and covered broad themes regarding WEN management, the actual level of cooperation among government officials, level of integration, and the public policy process formulation. This allowed the study team to gather an in-depth understanding for each of the identified themes, explore areas that have not been investigated in the literature, and provided flexibility in arranging the questions during the interview (Edwards and Holland, 2013). Capturing responses to a number of similar questions on the topic from different perspectives helped gaining a good understanding and knowledge about the WEN in Jordan, while providing some structure for comparison across different interviewees (Edwards and Holland, 2013). Probing techniques were applied during the interviews to get the respondents to elaborate and expand on their responses and on any additional points they raised (Edwards and Holland, 2013). The use of leading or guiding questions was limited in order to maintain an acceptable level of impartiality and avoid unnecessary bias.

Interviews were primarily conducted in the local language (i.e., Arabic) and, with the participants' permission, were audio-recorded. The main points relevant to the study were transcribed and translated into English by the study team, guided by the audio recordings, which were used to interpret information shared. Verbatim transcriptions were only made for statements that were found extremely relevant and useful to the study. The study team prepared the interview protocol and gained the required consent from the participants in accordance with the ethics and integrity procedures of the University of Surrey Ethics Committee. 
Interviews were analyzed using a thematic analysis process. Thematic analysis is a qualitative research method that is used to explain and interpret participants' perspectives by identifying themes within the collected data (Nowell et al., 2017). The study team first reviewed the transcripts individually, and from each extracted a number of points that found relevant to the broad themes identified initially and the interview questions. Findings were then grouped and organized into categories to allow the study team to synthesize and interpret the data. This involved identifying linkages, overlaps, differences, and similarities (Nowell et al., 2017) between the answers for the same questions, as well as explaining and evaluating the concepts and themes extracted from the responses. Lastly, the data gathered from the 'elite' group of experts were triangulated in line with the relevant literature on the WEN and the findings of the public policy mapping in Jordan as explained in 3.1 above.

\subsection{RESULTS AND DISCUSSION}

\subsection{Level of Understanding of the WEN}

All the participants in this study acknowledged the necessity of considering the interrelationship between the water and energy sectors to address the country's environmental challenges. However, the level of understanding and knowledge of the 'nexus' approach varied among officials in the two sectors, and it was driven by different interests. Water sector officials were concerned with minimizing the impact of energy consumption and its cost on the sector while improving the energy efficiency of the service. They explicitly expressed the need for more studies on the WEN, which they consider a new field. Conversely, energy sector officials were mostly concerned with achieving the targets and plans set in the energy sector reform policies, and with diversifying the energy sources. Little attention was given to water, and respondents were more conservative in terms of sharing information regarding collaboration at the policy and institutional level. These variations are attributed to the limited impact of the water sector on the energy sector, as justified and perceived by the energy sector officials, as well as the physical dependency of the water sector on energy (for generation, distribution, pumping, etc.). For example, a high-level energy official said:

We, at the ministry [MEMR], are aware of the WEN as an emerging topic that we are still learning about. However, most of the power stations and generation plants in Jordan are equipped with dry cooling systems; which limits the energy sector consumption of water. Our main priority is to achieve reductions in the share of imported energy and maximize the use of domestic sources for generation. We certainly have constant collaboration with our peers in the other entities including those in the water sector, but most of the efforts are done internally. (ESO1)

These observations were also observable in the key energy sector strategies prepared by the government (i.e., National Energy Efficiency Strategy (2005-2020) (MEMR, 2004), Updated National Master Strategy for Energy Sector (2007-2020) (MEMR, 2007), and Energy Sector Strategy (2015-2025) (MEMR, 2015)). These documents are mainly focused on improving 'Energy Efficiency (EE)' and increasing the share of renewables in the energy mix. Consequently, from an energy management perspective, there is no evidence of integration at the technical, policy development, or governance levels between the water and energy sectors.

In contrast, it was observed that more focused and pragmatic efforts are undertaken by the water sector toward better WEN governance. As confirmed by two high-level water officials (WSO1, WSO3), these can be summarized as:

- Collaboration with other government parties and international organizations and donors on the adoption of Energy Efficient Measures (EEM) (i.e., measuring and monitoring the efficiency of the pumps available on the groundwater wells; process optimization and design 
adjustments for all treatment plants; reviewing the potential and impact of utilizing energy efficient equipment, technologies, and pumps on energy reduction);

- The utilization of 'Renewable Energy (RE)', mainly: 1) solar energy through PV facilities; 2) hydropower, where elevation difference allows; and 3) sludge and biogas as an energy source in treatment plants.

These activities suggest that the level of awareness is increasing among water officials about the importance of adopting nexus thinking in water planning. This claim is evident in the water sector policies prepared between 2008 and 2016. Figure 3 shows the incremental progress observed in the water policies in Jordan in terms of WEN consideration.

Jordan's Water Strategy (2008-2022) has set the pace for long-term planning for water sector reform and development (until 2022), through setting a number of core principles and targets to be achieved by then; mainly achieving continuous supply of water and exploring alternative sources for water supply such as desalination. Nonetheless, it can be argued that it is entirely sector-oriented and does not explicitly address the impact of some of the cross-cutting themes in the water sector including energy. For example, it demonstrates the need for an effective energy management within the sector, recognizes the importance of reducing the energy cost associated with the adoption of alternative water sources such as desalination, and highlights the need to work with other government entities and stakeholders to achieve this goal. Whilst the latter point could imply a potential for mutual collaboration, it can be argued that the strategy falls short in proposing actual policy and institutional mechanisms for this integration.

Subsequently, the National Water Strategy (2016-2025) comes in response to new challenges facing the water sector, namely the increasing demand for and cost of energy amplified by the refugees' crisis. The strategy presents the first practical attempt by the government to plan a comprehensive water sector development initiative that adopts a holistic approach in adherence with the UN's SDGs. It specifically considers the other sectors directly related to water consumption or production, namely the energy sector. This suggests that integration with energy decision makers and other related stakeholders is intended and supported. The EE and RE Policy for the Jordanian Water Sector (2016) ultimately lays out the basis for long-term energy management in the water sector. It adopts a results-oriented approach to understand the physical connection between water and energy, and proposes results-based measures to minimize trade-offs between the two sectors. Encouragingly, this suggests that efforts to understanding the interaction between the two sectors have started to be systematically embedded, at least at the technical level. Targets are identified and set for the following years, in reference to base year estimates.

The progress in the water policies implies the openness and flexibility of the water sector to adopt new paradigms for long-term planning and holistic governance approaches. One of the high-level water officials put it as:

$W e$, at the MWI, are very interested in exploring any idea that would help us meet the sector challenges, particularly the energy challenge. We have started actual efforts in this respect, which translate into unorthodox ways of executing different projects within the water sector. I call it a "paradigm shift" in understanding the WEN. (WSO1)

This finding disrupts previous assertions (e.g., Scott et al., 2011) that a change toward coupled governance between water and energy would be more likely to happen when it is initiated by the energy sector. Instead, it indicates that water polices could provide the scope and have the flexibility to drive the change for better WEN governance, especially when energy policies fail to do so (a point demonstrated in the discussion of energy policies in 4.2 below), and in developing countries facing financial and natural-resources strains. Notwithstanding the need for a major cross-sectoral revamp of the governance structure to address the WEN, vertical coordination 
and tackling the nexus-governance issues across the administrative levels (Pahl-Wostl et al., 2018) within each institution would accelerate the transition toward an integrated WEN collaboration. This openness, when accompanied by a solid political commitment from the water sector institutions, could even influence a change in the behavior of energy sector's institutions, which in turn promote 'institutional interaction' (Oberthür and Gehring, 2006; Weitz et al., 2017a) and the development of shared WEN governance objectives.

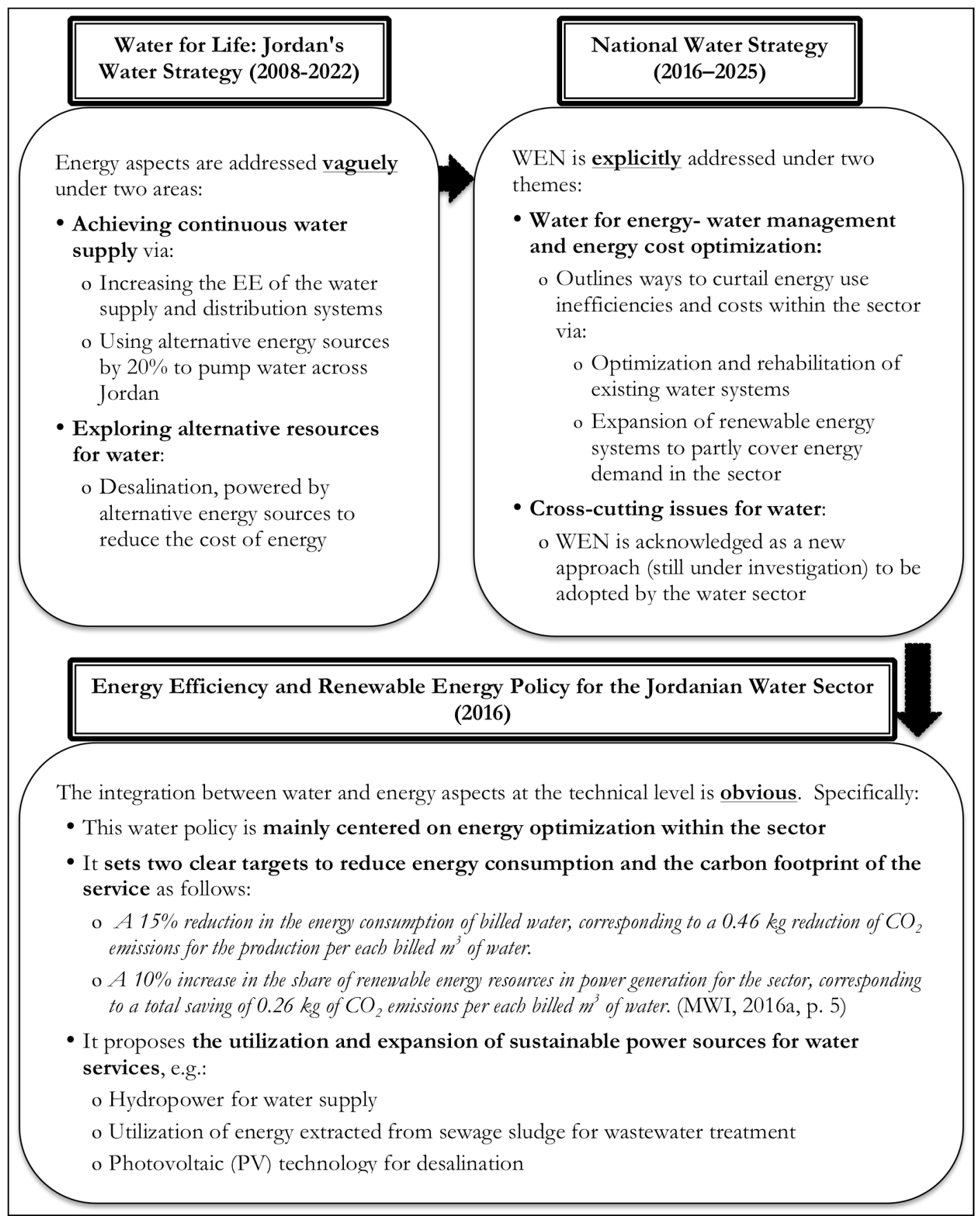

Figure 3: Progress in the Water Sector Policies in Jordan Regarding WEN Consideration

Nonetheless, the participants agreed that more is yet to be done regarding WEN understanding, particularly in the areas of long-term capacity building, institutional building, and know-how. The majority of the respondents agreed that increasing the level of awareness of the top-level decision makers, policymakers, engineers, and other public sector officials about the WEN and 
its concepts and application is a necessity for efficient adoption of the nexus approach to managing resources. A former water sector official claimed that in order for a change to happen in the public sector, a drive from policymakers and decision makers is needed (FWSO):

\section{I think we are unlikely to see practical changes in the sectors' management until we see the top- level leaders understanding what the WEN is, and appreciating its potential in facilitating inter-sectorial management schemes to save our natural resources. (FWSO)}

A sustainability advisor stressed the need for a change in the mindset of public sector officials and other water and energy experts about this topic (SSN). In the area of the WEN, this can be achieved by increasing the capacity of the top-level officials, so they would disseminate the knowledge within their institutions, and trigger a drive for change (Weitz et al., 2017a). Collaboration with the private sector in this area is suggested.

The above findings confirm that the WEN is understood differently across the two sectors' officials, despite the common consensus on its merits. This translates into inadequate WEN governance and policy integration. It is therefore suggested that careful planning and design (Bhaduri et al., 2015) for the capacity-building programs in this regard (e.g., workshop activities, networking event, etc.) is needed to ensure achieving effective outcomes. Specifically, capacitybuilding programs need to focus on identifying priority areas in the WEN, common grounds and entry points that trigger collaboration, dissimilarities and specific interlinks between the two sectors, and which actors are involved (Al-Saidi and Elagib, 2017; Bhaduri et al., 2015; Leck et al., 2015; Weitz et al., 2017a). While this process normally takes time and effort (Weitz et al., 2017a; Bhaduri et al., 2015), it would ultimately guide policymakers to better identify the level of coordination needed and propose effective measures accordingly.

Another key aspect to drive and improve WEN implementation and governance would come through society education. Educating the public about the WEN challenges and opportunities via proper awareness campaigns would lead to informed public consultations, and in some cases 'public pressure' on policymakers, to adopt integrated sustainable approaches for resources governance. Public pressure is likely to occur in the developing world countries, specifically when governments fail to sustain the needs of the people (e.g., inadequate water services or spikes in electricity prices) due to ineffective planning. Society education is, however, a longterms process that requires collaboration from the government, private sector, and the NGOs to be reached. It also requires policymakers to prepare long-term energy and water models to be utilized while planning energy and water projects (Al-Saidi and Elagib, 2017; Bazilian et al., 2011), taking into account the social, economic, and environmental aspects of the projects.

\subsection{Level of Institutional Collaboration, Governance, and Planning}

Water sector officials admitted that efforts undertaken by the MWI regarding the WEN are not institutionalized. The ministry is working on an ad-hoc basis, mainly implementing the projects listed in the policy developed in this regard (i.e., 'RE and EE in the water sector policy'). No single department, unit, or institution within the ministry is currently responsible for the development of long-term plans related to the EEM or the utilization of RE in the water sector. Similarly, no formal coordination, at the planning level, with the MEMR or its relevant institutions exists in regard to the WEN. Water and energy sector officials confirmed that the only type of cooperation between the MWI and the MEMR is at the administrative and operational level; with regards to licensing, acquiring agreements and permits to synchronize with the national grid, and other coordination on some other operational procedures (ESO1, WSO1, WSO3). Respondents in both sectors highlighted that the process of collaboration is mainly done through official correspondences, most of the time though emails and official letters. Weitz et al. (2017a) argue that adopting such types of integration alone can fail to achieve policy coherence and cross-sectoral integration, both necessary to proper governance. This is a valid assertion, as some of the operational and administrative processes undertaken by decision 
makers in the two sectors may not be always unbiased (Kurian, 2017), as explained in the point on conflict between water and energy sectors in 4.3 below. It is thus suggested that other forms of integration be followed in the governance structures of the water and energy sectors, including forms built on "trust, ownership, engagement in knowledge assimilation, strategic thinking and interaction, and learning" (Weitz et al., 2017a, p. 170), to guarantee making a change.

The absence of actual WEN collaboration at the planning and governance level was further confirmed by reviewing the energy and water strategies in Jordan prepared between 2005 and 2015, and 2008 and 2016, respectively. Three energy strategies were developed in response to the increasing energy demand, new challenges hitting the sector, mainly the natural gas supply cutoff from Egypt, the high cost of renewable systems, and the lack of investments in electricity generation projects, which all hinder effective implementation of renewable electricity generation projects. Therefore, policymakers have focused on enhancing the EEM in all sectors, and increasing the share of renewables in the energy mix via developing a regulatory framework to fulfill these objectives. The strategies are also focused on reforming the energy market by steadily reducing oil and electricity subsidies, and promoting public sector participation in the field via financial exemptions. No evidence for integration between water and energy sectors was observed in any of the developed strategies, neither at the physical level nor at the policy development or governance level.

The Strategic Plan for Energy (2016-2018) came out to translate the strategic and sectorial targets that were proposed in the previous strategy into a set of indicators and projects. For each goal listed in the National Energy Strategy (2015-2025), this plan identifies key performance indicators and targets to be reached in reference to a base year, and established projects to be implemented under each target. The principal authority(s) responsible for the implementation, the supporting units, and related stakeholders were clearly identified in the plan. This implies an incremental change in the sector governance into a participatory approach to potentially minimize conflict of interests and fulfill the sector needs. Ironically, though, most of the stakeholders identified in the plan are those related to the sector internally (e.g., EMRC, NEPCO, generation companies, etc.), the main ministries that channel funding to the sector (e.g., MoPIC and the MoF), and other ministries related to the projects to be implemented. Given the nature of the proposed projects, which are mainly addressing strategic and sectorial targets in the energy sector, the MWI has little presence in this strategic plan. This finding supports the argument that for strategic projects such as the nuclear project and desalination, where water resources become an issue, it becomes vital for policymakers in the two sectors to identify how collaboration can be embedded at the outset of the project and during the early planning stages of it.

Similar observations in terms of the level of integration can be drawn from the developed water strategies. While the National Water Strategy (2016-2025) is accompanied by an action plan and a set of recommendations, it can be argued that most of the proposed plans and actions are sector-centric in terms of their implementation. The strategy stresses the need for inter-sectorial collaboration to achieve the development targets, but it does not set forth how this collaboration can be achieved, at what level, and what potential mechanisms should be deployed to achieve this purpose. This is crucial when strategic development projects with potentially high impact are identified (e.g., nuclear power plant, oil-shale, and Red Sea-Dead Sea water conveyance projects). Currently, large scheme projects and investments are still being planned separately, on a project-by-project basis, in the absence of an integrated policy, formal protocol, and established process for this. Water sector entities are assumed to propose only plans to maximize energy efficiency and reduce energy cost, and to work with the stakeholders within the sector to achieve the anticipated targets. The type of integration with the energy sector, according to the strategy, is that plans proposed by the water sector entities need to be developed in line with the ongoing strategies pertaining to the energy sector (e.g., national energy 
strategy 2007-2020). Hence, the water sector needs to review the laws and regulations governing EE implementation, for instance, in order to identify the best options that can be achieved. These arrangements imply a single effort within a single ministry.

As for the EE and RE Policy for the Jordanian Water Sector (2016), details on the integration at the policymaking process and governance level remain modest. For instance, this policy identifies the key participant institutions (government and private) and their roles to achieve the policy targets, a detail that was overlooked in the previously developed policies. Nonetheless, the roles of those institutions are listed only vaguely under broad categories such as policy formulation, coordination, monitoring and evaluation; licensing and issuing permits; funding and financial regulation; environmental protection and ecological aspects; and implementation and participation. The obscurity in identifying the roles, rights, and responsibilities of each institution involved in the WEN governance across the two sectors implies weak policy coherence (Pittock et al., 2013; Weitz et al., 2017a), which makes formal integration a challenge unless elaborated and exhaustive policies are put in place.

Moreover, the level of fragmentation in the policy design and implementation suggests that a clear mechanism for collaboration at the formal level to govern the formulation of policy and its implementation, and to guarantee its effectiveness is missing. This, combined with a relatively limited understanding of the complex 'water-energy resources' relationship (Al-Zu'bi and Keough, 2015; Hoff, 2011), exacerbates the losses in the two sectors (Boas et al., 2016), as it leads to independent and disconnected solutions to meet the challenges in the two sectors (Hussey and Pittock, 2012).

Many of the respondents believed that good human resources with advanced experience and expertise, knowledge, transparency, and know-how would help institutionalizing the process of developing effective and integrated resource management plans (ESO1, ESO2, WSO1, WSO2, $\mathrm{SSN}$ ). Added to these is the need for identified investments with a clear time plan and vision re: a) the types of the proposed projects, b) their location, c) their connection to other existing or planned projects, and d) expected capacity and benefits (WSO1). The respondents' perspective on investments offers two significant insights, and the two interlink. The first is the nexus role as a driver for economic growth (Bazilian et al., 2011) through investments, while the second is the role of investments, as enabling factors, for gearing a better change in the WEN governance. It can be argued that a gap in the water and energy infrastructure and services will likely to accrue in the Middle East region, especially in Jordan, due to the growing demand on resources and the lack of financial capital to fund public-service investments in this context (Keulertz and Woertz, 2015). In order to fill this investment gap, the WEN will therefore act as a catalyst to attract 'green' investments (e.g., promoting the use of renewables in the water), from both external and internal funding sources (e.g., via international and local loans, grants, and most preferably private sector development and participation (Keulertz and Woertz, 2015)). To achieve an impact though, this requires better governance of the WEN through a combination of integrated management, cross-linked institutional frameworks, and shared objectives and targets to improve policy coherence and institutional integration (Weitz et al., 2017a), which are considered keys for effective private sector participation in this regard (SSN).

\subsection{Barriers for Effective WEN Coordination between the Water and Energy Sectors}

A number of factors were identified in this context. According to the water sector officials, the MEMR is the major hindrance for effective integration between the water and energy sectors. This is mainly driven by economic and financial factors. The MWI and its distribution companies, which are spread across the country (central, northern, and southern water companies), are the largest consumers of electricity (WSO1, WSO3). This makes the water sector the largest source of revenue for the electricity market. Furthermore, given the geographical monopolization of the electricity sector in Jordan, the MWI and its companies have 
to rely on the electrical distribution companies and NEPCO, as the main source for energy and electricity. Water sector officials stated that the resistance from the energy sector, particularly the electricity distribution companies, to let the water sector depend on renewable energy sources is a key obstacle for progressing toward better WEN governance. A high-level water official explained:

We, at the MWI, are hit hard by the increasing prices of electricity. Reducing the energy bill of
the Ministry has become our priority. This will help us sustain the level of service and invest in
implementing more water supply projects. We in Jordan have the needed regulatory framework
(Law No. 13/2012) to benefit from renewables by wheeling and net-metering schemes.
Therefore, we are designing projects to utilize RE, but most of the times the process is delayed by
the MEMR, while it passes through administrative and operational procedures. Our sector is
the largest and most payable consumer for the electricity companies, and I think this doesn't
work in our favor in terms of energy cost savings. (WSO1)

Despite the presence of clear and robust laws and regulations governing RE integration, actual implementation is still modest and difficult. The Renewable Energy and Energy Efficiency Law (No. 13/2012), for instance, allows the MEMR to work with other specialized entities to conserve energy and increase energy efficiency in different sectors (Article 3c). While this could imply collaboration with other stakeholders, it can be argued that most of this collaboration, if it happens, is done internally with stakeholders within the energy sector (e.g., electricity distribution companies, generation companies, suppliers, and private energy sector, etc.), and with other ministries directly involved in the projects, namely MoPIC for project financing. The Law further allows for tendering of renewable energy projects through wheeling and net-metering schemes. This paves the way for other sectors, including the water sector, to invest in this area to meet the sector's objectives regarding energy optimization. On the one hand, the netmetering scheme allows the MWI to generate electricity in some of its stations by utilizing the solar energy via PV facilities connected to its stations' pumps. Those pumps, however, rely on the national grid for energy during the night, given the absence of energy storage facilities. This scheme reduces the full dependency on the national grid for electricity consumption; hence, decreases the cost of energy (WSO1, WSO3). The wheeling scheme, on the other hand, allows the MWI to establish RE facilities (e.g., PV facilities) in areas owned by the ministry and located away from the consumption centers (e.g., plants, pumps, stations, etc.). Those RE facilities are then connected to the national grid and the generated electricity is sold to NEPCO, through an agreement between the MWI and NEPCO (WSO1, ESO1). This lets the ministry to offset the difference between the actual consumption from the grid and the sold quantities on a quantity basis; thus, reduce energy bill. Nonetheless, this yet implies that work is being done as standalone initiatives by the concerned sectors (e.g., water), with no formal mechanisms to increase integration for the WEN. This can be mainly attributed to the inadequacy of the existing institutional mechanisms that are currently undertaken in the water and energy sectors, which are characterized by wide dispersion of the responsibilities concerning the WEN management across different public entities and at different decision-making levels (Leck et al., 2015). Such arrangements increase the complexity of integrated coordination (Pittock et al., 2013; Scott et al., 2011); thus, hamper better governance of the nexus and the advancement of putting the WEN in practice (Leck et al., 2015).

Other respondents argued that there is a gap between the laws and regulations, which can hinder achieving sustainable development in the country; contrasting the above point about having a complete good enabling environment. A sustainability advisor claimed that the laws concerning water, energy, and environment are "compartmental" (SSN), and the absence of a binding policy and in some cases the specific sectorial law hinder progress in this regard (SSN). Other uncontrollable factors such as political interests and individual and group interests are very visible in Jordan; they can have significant influence on lobbying for investment projects in line 
with their interests, particularly in the energy sector, according to a former high-level energy official.

Some respondents attributed the lack of coordination between the energy and water sectors to overlap in the policy objectives formulated for each sector. A high-level water official said "... each sector has developed its own policies and action plans, sometimes with the same objectives but the implementation runs in separation." (WSO2), which might trigger conflict. Conflict was interpreted differently by the energy and water respondents. From a water perspective, this includes: delay from the MEMR to give the required access on the national electricity grid for energy produced from wheeling projects implemented by the MWI (WSO2), resistance from the MEMR and the distribution companies to buy electricity generated from MWI projects, and delay in reviewing and conducting grid impact studies requested by the MWI (WSO1, WSO3). These all impede the MWI's effort to move forward in the RE projects, according to water officials. From an energy perspective, conflict takes the form of increased pressure on the national grid, which might interfere with the MEMR plans for expansion (ESO1, SSN). The findings above imply that overlaps in some of the procedural obligations, objectives, and documentation can be overwhelming for organizations to operate effectively, to the extent that they nearly "get to the point of inactivity" (Lachapelle et al., 2003, p. 483) in responding to the challenges (Lachapelle et al., 2003). This becomes worse in a messy situation or context (e.g., region, maturity of the governing system, etc.), where several other factors are involved. Nonetheless, it can be argued that such overlaps can also represent 'spaces' in which to develop coordinated responses and improved integration, especially if they are clearly identified and reviewed to spot redundancies.

As part of a wider nexus governance structure, Al-Saidi and Elagib (2017) argue that attaining better understanding of the nexus approach within the government and public sector entities would strengthen the government's role in controlling activities relevant to the nexus. The "institutional and people integration" (Al-Saidi and Elagib, 2017, p. 1136) can be achieved through understanding the 'state of integration' within the WEN (e.g., the levels and types of integration between institutions and other participatory arrangements), toward better integration at the institutional level. Such participatory arrangements can be simple institutional and policy arrangements (e.g., guidelines development/update) or mega-institutional arrangements (e.g., institutional restructuring- super ministers). While the choice of the suitable arrangement depends on different factors, most notably the understanding of the nexus (Al- Saidi and Elagib, 2017), other factors such as region, context, maturity of the institutional structure, and enabling environment, among other points, do count. In Jordan, most of the respondents agreed that institutionalizing the work on the WEN and ensuring effective planning and governance in this respect cannot be achieved in isolation (SSN, WSO1, WSO3). According to the respondents, this entails appropriate institutional restructuring to influence the formulation of integrated water-energy policies and better structures to deliver effective nexus-focused governance. This does not strictly imply supporting simple interlinked institutional and regulatory arrangements across the two sectors, but also advocating effective enforcements supported by legal means and sufficient allocation of financial resources (Scott et al., 2011) to power and guarantee proper implementation of the restructuring alternatives.

According to the sectors' officials, more efforts need to be established within each ministry to improve the integration between water and energy aspects; first within each ministry and then expanding the collaboration with the other concerned ministries. This leads to an incremental and steady change that would ensure the sustainability of the reform efforts. Despite this seems a counterintuitive form of integration; Oberthür (2009) argues that such level of "unilateral management by individual institutions" (Oberthür, 2009, p. 376) may contribute, in some cases, positively to the inter-institutional coordination and institutionalization of the interaction between institutions. Within the water sector, for instance, institutional arrangements for such collaboration, according to some senior water officials, could follow the pathway illustrated in 
Figure 4. In Jordan, such collaboration arrangement can be further considered as entry point toward 'integrated WEN governance'. This perspective is driven by the fact that institutions in the water and energy sectors have different organizational structures, management cultures and policies, and are guided by sector-specific targets and regulatory frameworks (White et al., 2017). Accordingly, institutions that are most likely to express power and interest in embracing the nexus approach in their management; water sector institutions in this case, can be therefore identified as key contributors to the long-term integration in the WEN (White et al., 2017).

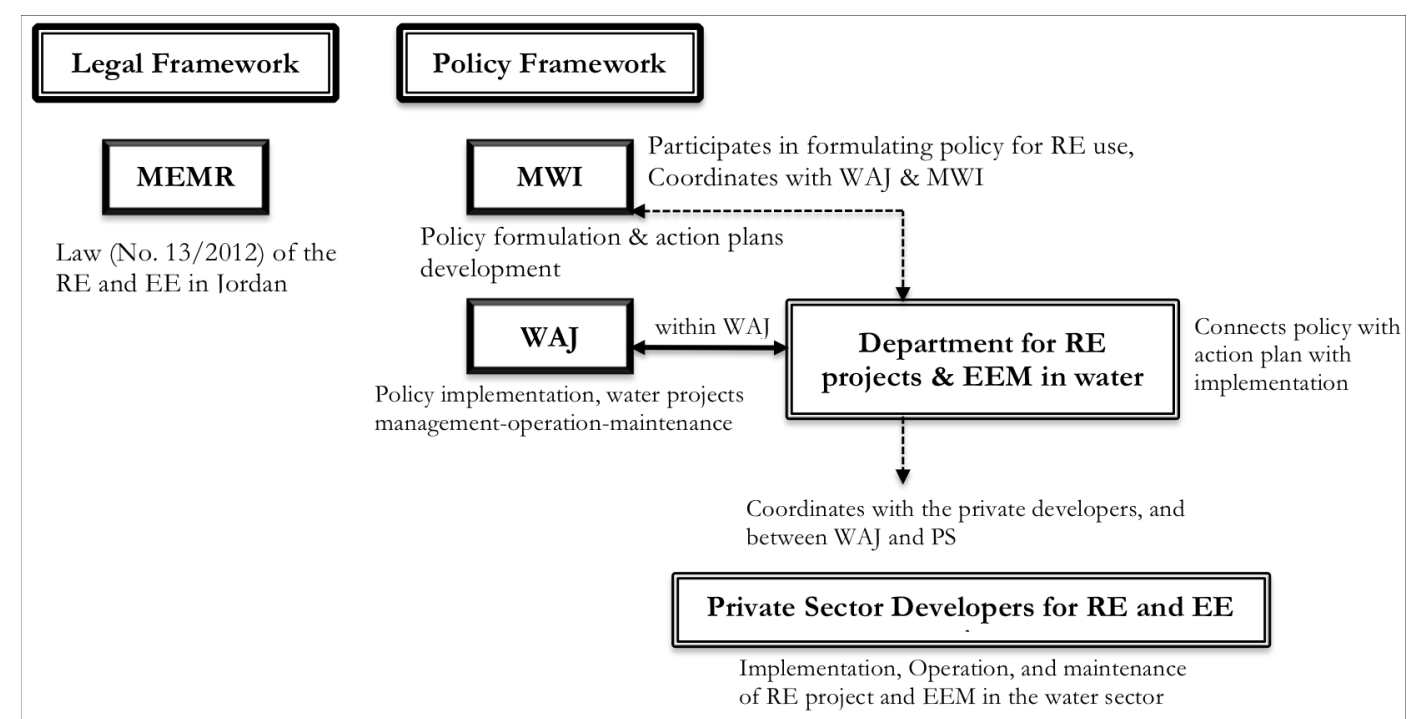

Figure 4: Proposed Institutional Arrangements for better WEN Governance in Jordan

This 'multi-layer approach' suggests that in order to achieve effective implementation of the RE projects within the MWI, better WEN governance and proper integration could evolve through adoption of appropriate legal and policy frameworks and private sector participation.

The MEMR would be a major player in this setting, and act as the legislative body. It has the legal framework necessary to facilitate the utilization of RE in projects, implementation of RE projects, and the application of EEM in this area, as enacted by (Law No. 13/2012) of the Renewable Energy and Energy Efficiency in Jordan.

The water sector institutions would act as the institutional body for this. Within the sector, the MWI has the policy framework, and is responsible for the policy formulation and the development of pragmatic action plans for implementation. WAJ, on the other hand, is responsible for the policy implementation and the service provision, operation, and maintenance. In the case of non-traditional projects such as those involving RE or the utilization of EEM (e.g., implementing and operating a new RE plant, or operating a WWTP based on digestion), a senior water official admitted that assigning sufficient expertise and in-house capacity might be a challenge (WSO1). To overcome this issue, a number of respondents suggested that outsourcing the service of implementing RE projects and EEM within the water sector to private developers specialized in this area would be beneficial (FESO, SSN, WSO1). From the perspective of Jordanian policymakers in the water and energy sectors, outsourcing such services to the private sector to implement, operate, and maintain the projects would increase the efficiency of those projects. This is due to the better exposure of the private sector to new technologies in the field, and the sector's capacity to maintain the projects and ensure that the life cycle of the project is sustainable. It can be argued that this perspective mainly stems from the private sector's ability to assign and allocate sufficient human and financial resources at a faster pace than the governments could afford, particularly in economically stressed countries 
(Bhaduri et al., 2015; Keulertz and Woertz, 2015; Kurian, 2017). The success of this process, however, requires careful selection of suppliers, clearly identified monitoring systems, and a robust regulatory framework to facilitate private sector involvement and guarantee its effectiveness to achieve the target outcomes.

Within WAJ, having a separate department dedicated to the RE and EE projects in the water sector would help institutionalize the efforts. The department would be responsible for ensuring that policies are connected with the action plans, along with its implementation. It would also coordinate between WAJ and the MWI in terms of planning for RE projects, participate in the policy formulation regarding renewables in the water sector, coordinate with other stakeholders (e.g., MEMR, MoE, etc.), as well as supervise the operations of the private developers in the RE facilities, and coordinate between the private developers and WAJ. Coordination between the key players would allow for effective planning and management, as well as monitoring of the RE projects within the sector. This would ultimately provide better understanding for the role and impact of the energy efficiency measures and RE projects on improving the sustainability of water sector management and its environmental impact.

It can be argued that the foregoing collaboration arrangement represents a sound proposal for institutional change to occur toward integrated governance in the WEN. This perspective is based on three main facts. First, the proposed arrangement stems from and aligns with the existing institutional structures and linkages in the two sectors. Evidence from the literature suggests that new institutional strategies would be more effective when assimilate into existing arrangements and support the sectors' outlooks and interests (Nilsson and Eckerberg, 2007). Consequently, institutional integration would take place (Al-Saidi and Elagib, 2017), and stronger political and decision-making influence would be ensured (Nilsson and Eckerberg, 2007). Additionally, improving the capacity within the existing institutions via involvement in the WEN thinking would allow better planning of collaboration mechanisms to develop (Bhaduri et al., 2015). Second, the arrangement assigns a major role for the private sector engagement in the process. Involvement of the private sector would enhance the formulation of a participatory governance scheme, involving several stakeholders, to effectively address the shared needs, requirements, and challenges of an integrated WEN management (Bhaduri, et al., 2015; Keulertz and Woertz, 2015; Kurian, 2017). Third, the outline of this arrangement is based on stakeholders' perspectives on the most convenient ways to achieve integration in the WEN. This makes the proposed suggestions practically executable to achieve an impact, and gives it the flexibility needed to adapt to future changes and subsequently further improve in this respect. For this transition to happen, however, a combination of: a) strong political support and collaboration at the higher levels of the WEN management (Nilsson and Eckerberg, 2007), to drive the change; b) frequent and extensive consultations with the relevant stakeholders on the shared objectives and targets necessary for nexus collaboration (Leck et al., 2015), to combat potential resistance to change; and c) better enabling environment for private sector participation, is a must.

\subsection{CONCLUSION}

Analyzing the water and energy sectors from a nexus perspective shifts the focus from a sectorspecific to a cross-sectoral management and lateral thinking approach, inclusive of other social, economic, and sustainability pillars (Al- Saidi and Elagib, 2017). This nexus paradigm paves the way to bring together sectors, instead of trying to manage these developmental domains separately (Al-Saidi and Elagib, 2017). This is particularly crucial when the nexus is investigated in water-scarce regions, where the vulnerability of the water sector as a resource and a service is high.

In the case of Jordan, it was observed that some institutions have been starting to embed the WEN thinking in their action plans, policies, and management efforts. These efforts, which are 
mostly practiced in the water sector, are sector-centric and address the physical integration aspects of the WEN. Notwithstanding its significance, understanding the physical integration of the WEN solely does not necessarily mean better integration to achieve desired sustainability outcomes (Siddiqi et al., 2013). Given that water and energy sectors are managed by, and closely related to, a wide spectrum of stakeholders, a number of policies have been developed, many of which undergo frequent updates and revisions, in a pace similar to the changing environment (e.g., complex energy challenges, increased fuel prices, impact of refugees, etc.). While each strategy comes with different level of details and updated context, energy and water policies are missing an aspect related to the integrated management, governance, and policy formulation in the WEN. One observation that can be generalized on those policies is the overlap in the content of the subsequent strategies. This is mostly observed in the energy sector, where the subsequent energy strategies, for instance, share almost the same targets with an overarching objective of achieving energy security. The policy incoherence observed in the two sectors increases the complexity of shifting toward integrated coordination and better governance of the nexus in reality. This limitation in the policy development output calls for further investigation. It also demands robust governance, institutional, and policy frameworks in order to govern the decision-making process across the sectors to foster management collaboration among line departments and ministries, and eliminate tension among them. This can be achieved through adopting tailor-made structures for multi-sectoral integration that follow simple institutional arrangements (e.g., regulatory update) or more complicated ones (e.g., institutional restructuring) (Al-Saidi and Elagib, 2017), or a combinations of both, supported by effective enforcements and adequate human and financial resources (Scott et al., 2011) to ensure achieving an impact. Given the diversity of the alternatives, a 'one-fits-all' model is not likely to be effective in this case; thus, the selection of the best arrangement needs to take into account the context where it applies. The 'multi-layer approach' proposed in this study presents an example for this, as it evolved from stakeholders' feedbacks and considered the existing institutional structures in the process.

Addressing the aforementioned points is not a straightforward task in water-scarce countries in the developing world, given the differences in interests and agendas of the different groups. Consequently, attaining better understanding of the nexus approach within the government and the public sector entities would strengthen the government role in controlling the activities pertaining to the nexus, as a key part within the wider WEN policy framework (Al-Saidi and Elagib, 2017; White et al., 2017). This can happen by designing capacity-building programs and activities that address specific points related to the WEN, and focusing on integration and participatory arrangements (e.g., involvement of the private sector) to promote investments as enabling factors to motivate integrated WEN governance. Other key factors include bridging the legal gap between laws and regulations; and developing binding polices and framework laws to avoid glitches, such as formulating regulations in favor of one sector to the detriment of others. Proposing a cross-sectorial committee comprised of water and energy officials at the Cabinet level is also a key to provide the needed political support, and study relevant projects in an integrated fashion; thus, recommend evidence-based decisions accordingly.

Findings of this study encourage further investigation to understand the relationship between the sectors officials in the context of WEN governance. While achieving physical integration between water and energy projects is important, particularly in water-scarce and economically stressed countries, better communication between the two sectors' officials would be advantageous. Identifying and understanding the factors that will a) improve communication between the water and energy sector players and policymakers, and b) influence the formulation of cross-disciplinary water-energy public policies to achieve better WEN governance structures is suggested as promising aspects for the WEN conceptualization research. Getting the sectors' stakeholders consensus on the most appropriate factors would further contribute to the understanding of the WEN at the institutional and policymaking levels. 
Funding: This research did not receive any specific grant from funding agencies in the public, commercial, or not-for-profit sectors.

\section{References}

AL-ANSARI, T., KORRE, A., NIE, Z., AND SHAH, N., 2015. Development of a life cycle assessment tool for the assessment of food production systems within the energy, water and food nexus. Sustainable Production and Consumption, [online] 2, pp. 52-66. Available at: <http://dx.doi.org/10.1016/j.spc.2015.07.005>.

Allouche, J., MIDDleTON, C., AND GYAWALI, D., 2015. Technical Veil, Hidden Politics: Interrogating the Power Linkages behind the Nexus. Water Alternatives, [online] 8(1), pp. 610-626. Available at: $<$ http://www.idaea.csic.es/medspring/sites/default/files/Technical-Veil-Hidden-Politics-Interrogating-the-PowerLinkages-behind-the-Nexus.pdf $>$.

AL-SAIDI, M., AND ELAGIB, N., 2017. Towards understanding the integrative approach of the water, energy and food nexus. Science of the Total Environment, [online] 574, pp. 1131-1139. Available at: $<$ http://dx.doi.org/10.1016/j.scitotenv.2016.09.046>.

AL-ZU'BI, M., AND KEOUGH, N., 2015. Water, Energy, Food: The Problematic Aspects of the Transition from "Silo Approach" to "Nexus Approach" in the Arab Region. In: 'Innovations and Sustainable Solutions for the Water Sector in the Arab Region', January 11-15, 2015. Dead Sea, Jordan. Arab Water Week.

AQUASTAT, 2018. Long-term average annual precipitation in volume [online]. Food and Agriculture Organization (FAO). Available at: https://knoema.com/FAOAQST2018/aquastat. Retrieved on: 29 January 2019.

BAZILIAN, M., ROGNER, H., HOWELLS, M., HERMANN, S., ARENT, D., GIELEN, D., STEDUTO, P., MUELLER, A., KOMOR, P., TOL, R.S.J., AND YUMKELLA, K.K., 2011. Considering the energy, water and food nexus: towards an integrated modelling approach. Energy Policy, [online] 39, pp. 7896-7906. Available at: $<$ https://doi.org/10.1016/i.enpol.2011.09.039>.

BENSON, D., GAIN, A., AND ROUILLARD, J., 2015. Water governance in a comparative perspective: From IWRM to a 'nexus' approach? Water Alternatives, [online] 8(1), pp. 756-773. Available at: $<$ http://www.idaea.csic.es/medspring/sites/default/files/Water-Governance-in-Comparative-Perspective-FromIWRM-to-a-Nexus-Approach.pdf $>$.

BHADURI, A., RINGLER, C., DOMBROWSKI, I., MOHTAR, R., AND SCHEUMANN, W., 2015. Sustainability in the water-energy-food nexus. Water International, [online] 40(5-6), pp. 723-732. Available at: <http://dx.doi.org/10.1080/02508060.2015.1096110>.

BOAS, I., BIERMANN, F., AND KANIE, N., 2016. Cross-sectoral strategies in global sustainability governance: towards a nexus approach. International Environmental Agreements: Politics, Law and Economics, [online] 16(3), pp. 449-464. Available at: <http://dx.doi.org/10.1007/s10784-016-9321-1>.

DAHER, B., AND MOHTAR, R., 2015. Water-energy-food (WEF) Nexus Tool 2.0: guiding integrative resource planning and decision-making. Water International, [online] 40(5-6), pp. 748-771. Available at: $<$ http://dx.doi.org/10.1080/02508060.2015.1074148>.

EDWARDS, R., and HOLLAND, J., 2013. What is qualitative interviewing?. 1 $1^{\text {st }}$ ed. United Kingdom: Bloomsbury Academic.

ENDO, A., TSURITA, I., BURNETT, K., AND ORENCIO, P., 2017. A review of the current state of research on the water, energy, and food nexus. Journal of Hydrology: Regional Studies, [online] 11, pp. 20-30. Available at: $<$ http://dx.doi.org/10.1016/j.ejrh.2015.11.010>.

FARAjAlla, N., HAYDAMOUS, P., AND EL HAII, R., 2016. Water, Energy, Food Nexus: An Outlook on Public Institutions in Lebanon. Issam Fares Institute for Public Policy and International Affairs, Working Paper No. 35-Nexus Series August 2016. [online]. Available at: <https://scholarworks.aub.edu.lb/bitstream/handle/10938/21136/20160828_nexus_lebanon.pdf?sequence=1\&isAll owed $=\mathrm{y}>$.

FORAN, T., 2015. Node and Regime: Interdisciplinary Analysis of Water-Energy-Food Nexus in the Mekong Region. Water Alternatives, [online] 8(1), pp. 655-674. Available at: < http://www.water-alternatives.org/index.php/all-abs/270-a8-1$3 /$ file $>$.

GAIN, A., GIUPPONI, C., AND BENSON, D., 2015. The water-energy-food (WEF) security nexus: the policy perspective of Bangladesh. Water International, [online] 40(5-6), pp. 895-910. Available at: <http://dx.doi.org/10.1080/02508060.2015.1087616>.

HAMICHE, M., STAMBOULI, A., AND FLAZI, S., 2016. A review of the water-energy nexus. Renewable and Sustainable Energy Reviews, [online] 65, pp. 319-331. Available at: <http://dx.doi.org/10.1016/j.rser.2016.07.020>.

HENSENGERTH, O., 2015. Where is the power? Transnational networks, authority and the dispute over the Xavaburi Dam on the Lower Mekong Mainstream. Water International, [online] 40(5-6), pp. 911-928. Available at: <https://www.tandfonline.com/doi/10.1080/02508060.2015.1088334>.

HOFF, H., 2011. Understanding the Nexus: Background paper for the Bonn 2011 Nexus Conference. In: 'Bonn 2011 Conference The Water, Energy and Food Security Nexus Solutions for the Green Economy', November 16-18, 2011. Bonn. Stockholm Environment Institute.

HOFF, H., ALRAHAIFE, S., EL HAJJ, B., LOHR, K., MENGOUB, F., FARAJALLA, N., FRITZSCHE, K., JOBBINS, G., ÖZEROL, G., SCHULTZ, R., AND ULRICH, A., 2019. A Nexus Approach for the MENA Region-From Concept to Knowledge to Action. Frontiers in Environmental Science, [online] 7(48), pp. 1-14. Available at: < https://doi.org/10.3389/fenvs.2019.00048>.

HUSSEY, K., AND PITTOCK, J., 2012. The energy-water nexus: Managing the links between energy and water for a sustainable future. Ecology and Society, [online] 17(1), pp. 31-39. Available at: <http://dx.doi.org/10.5751/ES-04641-170131> 
KEULERTZ, M., AND WOERTZ, E., 2015. Financial challenges of the nexus: pathways for investment in water, energy and agriculture in the Arab world. International Journal of Water Resources Development, [online] 31(3), pp. 312-325. Available at: $<$ https://doi.org/10.1080/07900627.2015.1019043>.

KIM, H., YOON, S., CHO, E. AND KIM, J., 2015. A Study on Policy Directions for the Water-Food-Energy Nexus (I). Korea Environment Institute: Network of Institutions for Sustainable Development, Project Report 2015-13-02. [online]. Available at: < http://webbook.me.go.kr/DLi-File/091/023/009/5610666.pdf>.

KURIAN, M., 2017. The water-energy-food nexus: Trade-offs, thresholds and transdisciplinary approach to sustainable development. Environmental Science and Policy, [online] 68, pp. 97-106. Available at: $<$ http://dx.doi.org/10.1016/j.envsci.2016.11.006>.

LACHAPELLE, P.R., MCCOOL, S.F., AND PATTERSON, M.E., 2003. Barriers to Effective Natural Resource Planning in a "Messy" World. Society and Natural Resources, [online] 16(6), pp. 473-490. Available at: $<$ https://doi.org/10.1080/08941920309151>.

LECK, H., CONWAY, D., MICHAEL, B., AND REES, J., 2015. Tracing the Water-Energy-Food Nexus: Description, Theory and Practice. Geography Compass, [online] 9(8), pp. 445-460. Available at: $<$ https://onlinelibrary.wiley.com/doi/epdf/10.1111/gec3.12222>.

MINISTRY OF ENERGY AND MINERAL RESOURCES (MEMR), 2016. Annual Report for 2016 [in Arabic]. Jordan.

MINISTRY OF ENERGY AND MINERAL RESOURCES (MEMR), 2015. Energy Sector Strategy (2015-2025) [in Arabic]. Jordan.

MINISTRY OF ENERGY AND MINERAL RESOURCES (MEMR), 2004. National Energy Efficiency Strategy in Jordan for the period (2005-2020). Jordan.

MINISTRY OF ENERGY AND MINERAL RESOURCES (MEMR), 2007. Updated National Master Strategy of Energy Sector in Jordan for the period (2007-2020). Jordan.

MINISTRY OF WATER AND IRRIGATION (MWI), 2016a. Energy Efficiency and Renewable Energy Policy for the Jordanian Water Sector. Jordan.

MINISTRY OF WATER AND IRRIGATION (MWI), 2015. Jordan Water Sector Facts \& Figures. Jordan.

MINISTRY OF WATER AND IRRIGATION (MWI), 2016b. National Water Strategy 2016 - 2025. Jordan.

NILSSON, M., AND ECKERBERG, K., eds., 2007. Environmental Policy Integration: Shaping Institutions for Learning. 1st ed. London: Earthscan.

NILSSON, M., AND PERSSON, A., 2003. Framework for Analysing Environmental Policy Integration. Journal of Environmental Policy and Planning, [online] 5(4), pp. 333-359. Available at: < http://dx.doi.org/10.1080/1523908032000171648>.

NOWELL, L., NORRIS, J., WHITE, D., AND MOULES, N., 2017. Thematic Analysis: Striving to Meet the Trustworthiness Criteria. International Journal of Qualitative Methods, [online] 16, pp. 1-13. Available at: $<$ https://journals.sagepub.com/doi/pdf/10.1177/1609406917733847>.

OBERTHÜR, S., 2009. Interplay management: enhancing environmental policy integration among international institutions. International Environmental Agreements: Politics, Law and Economics, [online] 9, pp. 371-391. Available at: $<$ https://link.springer.com/article/10.1007/s10784-009-9109-7>.

OBERTHÜR, S., AND GEHRING, T., eds., 2006. Institutional Interaction in Global Environmental Governance: Synergy and Conflict among International and EU Policies. Cambridge, MA, USA: The MIT Press.

PAHL-WOSTL, C., BHADURI, A., AND BRUNS, A., 2018. Editorial special issue: The Nexus of water, energy and food- An environmental governance perspective. Environmental Science and Policy, [online] 90, pp. 161-163. Available at: $<$ https://doi.org/10.1016/j.envsci.2018.06.021>.

PITTOCK, J., HUSSEY, K., AND MCGLENNON, S., 2013. Australian Climate, Energy and Water Policies: conflicts and synergies. Australian Geographer, [online] 44(1), pp. 3-22. Available at: <http://dx.doi.org/10.1080/00049182.2013.765345>.

SCOTT, C., EL-NASER, H., HAGAN, R., AND HIJAZI, A., 2003. Facing Water Scarcity in Jordan: Reuse, Demand Reduction, Energy, and Transboundary Approaches to Assure Future Water Supplies. Water International, [online] 28(2), pp. $209-216 . \quad$ Available
http://cip.management.dal.ca/publications/Facing\%20Water $\% 20$ Scarcity $\% 20$ in $\% 20$ Jordan.pdf $>$.

SCOTT, C., KURIAN, M., AND WESCOAT JR., J., eds., 2015. The Water-Energy-Food Nexus: Enhancing Adaptive Capacity to Complex Global Challenges. In "Governing the Nexus", [ebook] Chapter 2, pp. 15-38. Switzerland. Springer International Publishing. Available at: <https://link.springer.com/chapter/10.1007\%2F978-3-319-05747-7_2>.

SCOTT, C., PIERCE, S., PASQUALETTI, M., JONES, A., MONTZ, B., AND HOOVER, J., 2011. Policy and institutional dimensions of the water-energy nexus. Energy Policy, [online] 39(10), pp. 6622-6630. Available at: $<$ http://dx.doi.org/10.1016/j.enpol.2011.08.013>.

SIDDIQI, A., AND ANADON, L., 2011. The water-energy nexus in Middle East and North Africa. Energy Policy, [online] 39(8), pp. 4529-4540. Available at: <http://dx.doi.org/10.1016/j.enpol.2011.04.023>.

SIDDIQI, A., KAJENTHIRA, A., AND ANADÓN, L., 2013. Bridging decision networks for integrated water and energy planning. Energy Strategy Reviews, [online] 2(1), pp. 46-58. Available at: <http://dx.doi.org/10.1016/j.esr.2013.02.003>.

WEITZ, N., STRAMBO, C., KEMP-BENEDICT, E., AND NILSSON, M., 2017a. Closing the governance gaps in the waterenergy-food nexus: Insights from integrative governance. Global Environmental Change, [online] 45, pp. 165-173. Available at: <http://dx.doi.org/10.1016/j.gloenvcha.2017.06.006>.

WEITZ, N., STRAMBO, C., KEMP-BENEDICT, E., AND NILSSON, M., 2017b. Governance in the water-energy-food nexus: Gaps and future research needs. Stockholm Environment Institute, Working Paper No. 2017-07. [online]. Available at: < https://www.sei-international.org/mediamanager/SEI-2017-WP-Nexus-Governance-Weitz.pdf>.

WHITE, D., JONES, J., MACIEJEWSKI, R., AGGARWAL, R., MASCARO, G., 2017. Stakeholder Analysis for the FoodEnergy-Water Nexus in Phoenix, Arizona: Implications for Nexus Governance. Sustainability, [online] 9(12), pp. 1-21. Available at: <https://doi.org/10.3390/su9122204> 